\title{
Degradation Evaluation of Mechanical Property for Modified 9Cr-1Mo Steel by Reversible Permeability
}

\author{
Chung-jong Bong ${ }^{1}$, Kwon-sang Ryu ${ }^{2 *}$, Seung-hoon $\mathrm{Nahm}^{2}$, and Eun Kyu Kim ${ }^{1}$ \\ ${ }^{1}$ Hanyang University, Seoul 133-791, Korea \\ ${ }^{2}$ Korea Research Institute of Standards and Science, Deajeon 305-340, Korea
}

(Received 5 October 2010, Received in final form 5 January 2011, Accepted 5 January 2011)

\begin{abstract}
The present work studies a nondestructive evaluation of the degradation of modified 9Cr-1Mo steel using a magnetic method based on the existence of the peaks of reversible permeability (RP) in the differential magnetization around the coercive force. The apparatus is based on detection of the voltage induced in a coil using a lock-in amplifier tuned to the frequency of the AC perturbing field. Results obtained for the reversible permeability and Vickers hardness on the aged samples showed the peak interval of reversible permeability (PIRP) and Vickers hardness decrease as aging time increased. The correlation between Vickes hardness and the PIRP could be used to evaluate degradation of modified 9Cr-1Mo steel.
\end{abstract}

Keywords : degradation, modified 9Cr-1Mo steel, nondestructive evaluation, peak interval of reversible permeability (PIRP)

\section{Introduction}

Recently, modified 9Cr-1Mo steel has been used in fossil power plants and petrochemical plants given its superior weldability and high-temperature strength. This steel has been used among the high temperature $\left(610^{\circ} \mathrm{C}\right)$ components of the steam power plants. The microstructural changes and solute segregation induced at evaluated temperature environments frequently produce severe degradation in terms of the mechanical properties of the steel [1,2]. Many researchers [3-5] have been interested in nondestructive measurement methods for examining microstructural changes and component damage in order to ensure safe operation of the steel structures, such as turbine rotors and reactor pressure vessels. Although various nondestructive methods have been studied, development of a nondestructive technique to quantitatively estimate material degradation has not been completed to date [3-5].

In this work, the authors isothermally prepared agedmodified 9Cr-1Mo steel samples and measured their tensile and yield strengths, Vickers hardness, and peak interval of reversible permeability (PIRP). The PIRP could plausibly be used to evaluate material degradation during nondestructive servicing of steel structures, such as turbine rotors and

*Corresponding author: Tel: +82-42-868-5164

Fax: +82-42-868-5018, e-mail: ryuks@kriss.re.kr reactor pressure vessels.

\section{Experimental procedure}

The test material for this experiment was modified 9Cr1Mo steel that had been used in power plant applications. Tensile specimens were taken from the plate material of the modified 9Cr-1Mo steel in the longitudinal direction. Tensile specimens of $6.4 \mathrm{~mm} \times 25.4 \mathrm{~mm}$ (diameter $\times$ gage length) were prepared. Yield strength, tensile strength, and elongation were measured according to ASTM E8 standards. A micro-Vickers hardness tester (HMV-2000, Future Tech., City, State, Country) was used to conduct a hardness test, with $500 \mathrm{gf}$ as the testing load. Samples with dimensions of $50 \mathrm{~mm} \times 25 \mathrm{~mm} \times 5 \mathrm{~mm}$ were prepared and aged at $690^{\circ} \mathrm{C}$ for as-received, $198 \mathrm{~h}, 458 \mathrm{~h}, 644 \mathrm{~h}, 820 \mathrm{~h}, 1,219$ h, 1,582 h, 1,941 h, 2,299 h, and 3,022 h as an accelerated aging process in an effect to simulate the microstructures of materials in service in steam turbines at a temperature of $610^{\circ} \mathrm{C}$ for approximately as-received, $25,000 \mathrm{~h}, 50,000$ h, 75,000 h, 100,000 h, 150,000 h, 200,000 h, 250,000 h, $300,000 \mathrm{~h}$, and $400,000 \mathrm{~h}$, respectively. This method was adopted to simulate the microstructures of materials in long-term service at elevated temperatures due to difficulties in obtaining aged materials on site. Thus, ten kinds of specimens with different microstructures were prepared. The periods of heat treatment for the simulation were 
Table 1. Decision of the aging times at $690^{\circ} \mathrm{C}$ for equivalent microstructure served at $610^{\circ} \mathrm{C}$.

\begin{tabular}{ccccrrrrrr}
\hline \hline $\begin{array}{c}\text { Heat treatment time } \\
\text { at } 690^{\circ} \mathrm{C}(\mathrm{h})\end{array}$ & 198 & 458 & 644 & 820 & 1,215 & 1,582 & 1,941 & 2,299 & 3,022 \\
\hline $\begin{array}{c}\text { Time served at } 610^{\circ} \mathrm{C}(\mathrm{h}) \\
\text { Larson-Miller parameter }\end{array}$ & 25,000 & 50,000 & 75,000 & 100,000 & 150,000 & 200,000 & 250,000 & 300,000 & 400,000 \\
22,42 & 21,822 & 21,965 & 22,066 & 22,229 & 22,341 & 22,426 & 22497 & 22,612 \\
\hline
\end{tabular}

selected based on the Larson-Miller parameter (LMP) as follows:

$$
L M P=T(C+\log t)
$$

where $T$ is the heat treatment temperature $(\mathrm{K}), C$ the material constant, and $t$ the heat treatment time (h). Because the change in this parameter is a function of time and temperature, its current value may be used to estimate an equivalent thermal history for a given operating time [6], summarized in Table 1.

The changes in reversible permeability (RP) were investigated by a lock-in amplifier. To measure the RP, the specimens were magnetized by a surface type probe with a ferrite yoke. The probe was constructed of a pickup coil, an AC perturbing coil, and a DC magnetizing coil [5]. The DC magnetic field was produced via a sinusoidal wave current of $0.05 \mathrm{~Hz}$ with a maximum applied magnetic field of $14 \mathrm{kA} / \mathrm{m}$. A ferrite yoke was used for measuring the RP in order to diminish the demagnetization effects of the open magnetic circuit. A lock-in amplifier measured the voltage in the pick-up coil with a reference as the perturbing field. The RP was chosen by selecting the reference mode at a single frequency. The slow varying magnetic field was measured via the current using the voltage across a shunt resistor of $1 \Omega$. The RP was measured during a cycle of slow varying field as a function of the current along the sample axis using an $\mathrm{I} / \mathrm{O}$ acquisition board [5].

\section{Results and Discussion}

In general, when a small perturbing field $h(t)$ with a slow varying field $H_{\mathrm{o}}$ is applied to a magnetic material, the perturbing field induces minor loops along a major loop. Proving that the magnetic process on the minor loop is the same as those on the major loop is difficult, but induced magnetization $m$ is phenomenologically expressed in the power series of $h$ [7]:

$$
\begin{aligned}
& H=H_{0}+h=H_{0}+h_{0} \sin (\omega t) \\
& B=B_{0}+b=\mu_{0}\left(H_{0}+M_{0}\right)+\mu_{0}(h+m) \\
& m=\chi_{1} h+\chi_{2} h^{2}+\chi_{3} h^{3}+\ldots
\end{aligned}
$$

where $\chi_{1}$ is the linear magnetic susceptibility component and $\chi_{2}-\chi_{n}$ are the nonlinear higher order components.

The induced magnetization causes the voltage $E\left(H_{\mathrm{o}}, h_{\mathrm{o}}\right)$ in a sample pick-up coil. $E\left(H_{0}, h_{\mathrm{o}}\right)$ is given by the time derivative of magnetic flux, which is proportional to the magnetization. $E\left(H_{\mathrm{o}}, h_{\mathrm{o}}\right)$ can then be expressed as follows [5]:

$$
E\left(H_{0}, h_{0}\right) \propto \frac{d m}{d t}=E_{1} \cos \omega t+E_{2} \sin 2 \omega t-\ldots
$$

with $E_{1}=A \omega\left(\chi_{1} h_{o}+(3 / 4) \chi_{3} h_{o}^{3}+\ldots\right)$

$$
E_{2}=A \omega\left(\chi_{2} h_{o}^{2}+\chi_{4} h_{o}^{4}+\ldots\right)
$$

where $m$ is an induced magnetization $(\mathrm{A} / \mathrm{m})$ and $A$ is a constant that represents the geometry of the pick-up coil. Of note are the coefficients of the odd harmonics $\left(E_{1}, E_{3}\right)$ derived from the odd powers that reflect nonlinear magnetization.

A $B$ - $H$ hysteresis loop, the RP, and an incremental permeability are shown in Fig. 1. Incremental permeability $\left(\mu_{\Delta}\right)$ refers to alternating field excitation for a specified static field value. The RP is the limiting value of the incremental permeability when the alternating field strength approaches zero [8].

The method to measure RP is based on the existence of

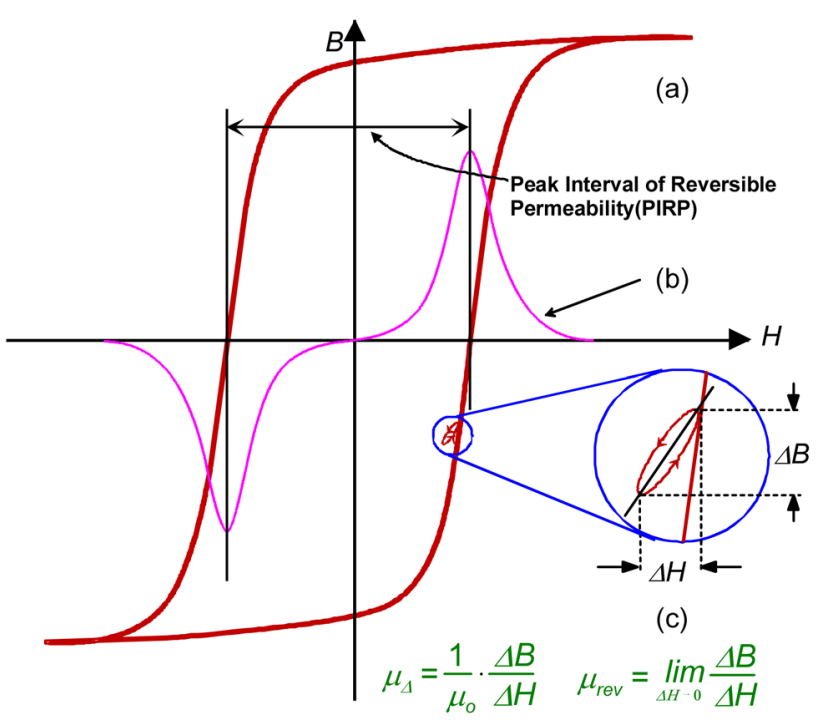

Fig. 1. Profiles of hysteresis loop and reversible permeability: (a) $B-H$ hysteresis loop, (b) profile of reversible permeability, and (c) incremental permeability. 


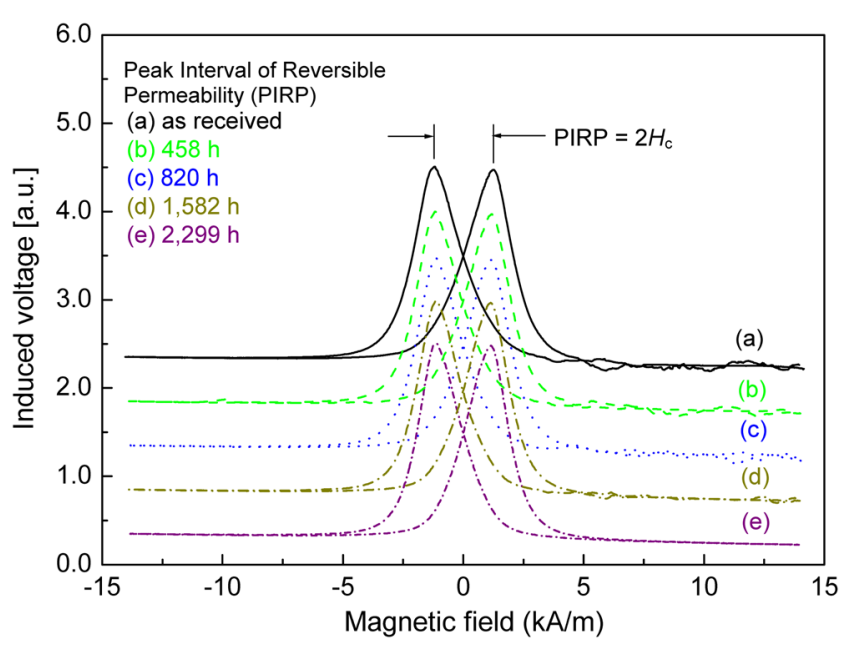

Fig. 2. Reversible permeability profiles for aging time: (a) asreceived; (b) $458 \mathrm{~h}$, (c) $820 \mathrm{~h}$, (d) 1,582 h, and (e) 2,299 h.

the peaks of RP in the differential magnetization around the coercivity. The peaks of RP based on heat treatment time are shown in Fig. 2. As shown in Fig. 2, the PIRP decreases along with an increase in aging time. This phenomenon can be explained by a magnetic softening, resulting from the migration of carbides towards the grain [9].

Fig. 3 shows the variations in the diverse properties of degradation for the modified 9Cr-1Mo steel [10]. As the aging time increased, the tensile strength and Vickers hardness decreased along with PIRP. The variation in yield strength normalized while those of a virgin sample decreased significantly for a short aging time, but the change becomes small at a long aging time. The decrease in magnetic and mechanical properties should originate such that the magnetic and mechanical softening of the matrix is likely to affect the properties of the sample more than the hardening of the grain boundary by carbide precipitations $[4,11]$.

In order to measure tensile and yield strength using more standard methods, the sample is gathered from the equipment in service; naturally, these methods are destructive. However, gathering a specimen for the material test without damaging the equipment is virtually impossible. The degradation evaluation of equipment in power plants by means of destructive methods is thus impractical. Identifying a reliable nondestructive evaluation technique for material degradation is thus necessary. The Vickers hardness test is used for evaluating the material degradation nondestructively. Therefore, this lab measured the Vickers hardness, revealing a tendency to decrease with the extent of degradation, although the data from the 1,582 $\mathrm{h}$ sample was an exception to this tendency.

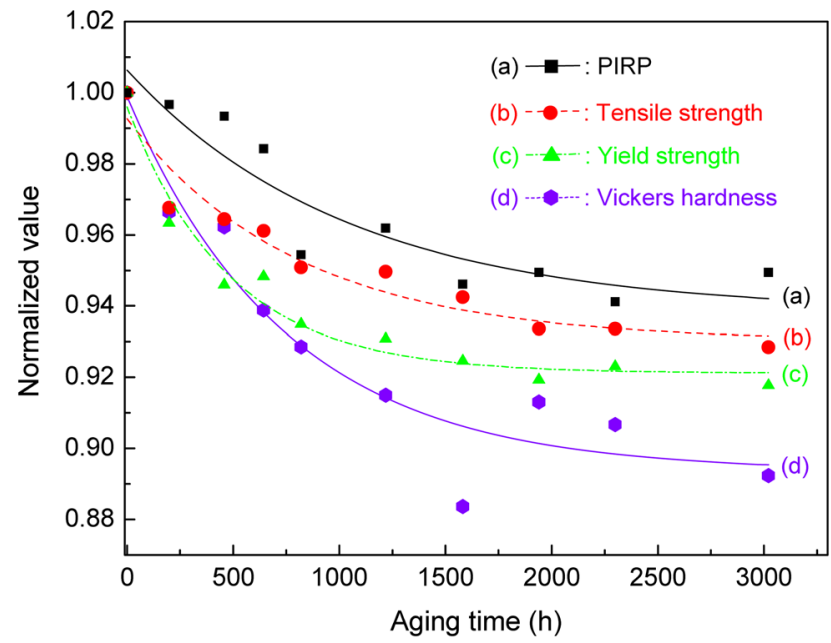

Fig. 3. Variation of tendency of normalized: (a) PIRP; (b) tensile strength, (c) yield strength, and (d) Vickers hardness on aging time.

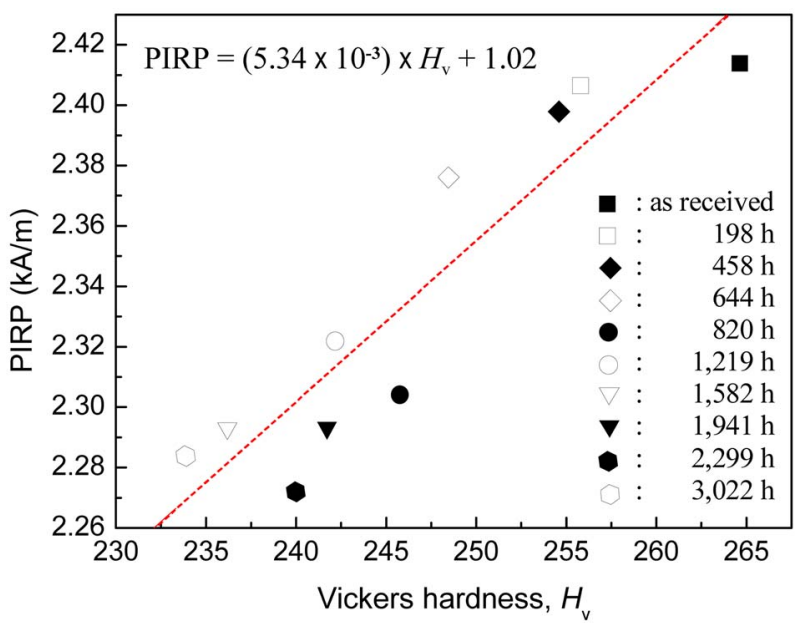

Fig. 4. Relationship between the PIRP and Vickers hardness with aging time. The PIRP increased linearly with an increase in Vickers hardness.

The PIRP increased linearly with the increase in Vickers hardness as shown in Fig. 4. The standard deviation for the PIRP for the Vickers hardness in Fig. 4 is 0.02 . The PIRP is given as a function of the Vickers hardness by the slope of Fig. 4:

$$
\text { PIRP }=\left(5.34 \times 10^{-3}\right) \times H_{v}+1.02
$$

These results indicate that the remaining life can be estimated from the existing relationship between the hardness and a life estimation parameter, such as the $G$ parameter (log value of $L M P$ [12]), even though only the PIRP is available. 


\section{Conclusions}

The RP signal was measured with a surface type probe and the PIRP decreased with increased aging time. The Vickers hardness was nondestructively measured by a micro-Vickers hardness tester and the value decreased with an increase in aging time. The linear relationship between the Vickers hardness and the PIRP showed that the change in mechanical properties could be effectively evaluated using nondestructive means. The PIRP could be used to evaluate the material degradation of modified 9Cr-1Mo steel.

\section{References}

[1] K. S. Ryu, S. H. Nahm, Y. B. Kim, K. M. Yu, and D. Son, J. Magn. Magn. Mater. 222, 128 (2000).

[2] W. B. Jones, C. R. Hills, and D. H. Polonis, Metall. Mater. Trans. A 22A, 1049 (1991).

[3] Y. Watanabe and T. Shoji, Metall. Mater. Trans. A 22A, 2097 (1991).
[4] K. M. Yu, S. H. Nahm, and Y. I. Kim, J. Mater. Sci. Lett. 18, 1175 (1999).

[5] K. S. Ryu, S. H. Nahm, J. S. Park, K. M. Yu, Y. B. Kim, and D. Son, J. Magn. Magn. Mater. 251, 196 (2002).

[6] R. Viswanathan, Damage Mechanism and Life Assessment of High-T Temperature Components, ASM International, Ohio (1989) p. 229.

[7] H. Negishi, H. Takahashi, and M. Inoue, J. Magn. Magn. Mater. 68, 271 (1987).

[8] R. Boll, Soft Magnetic Materials, Heyden \& Son Ltd., London (1979) pp. 36-37.

[9] A. Mitra, J. N. Mahapatra, J. Swaminathan, M. Ghosh, A. K. Panda, and R. N. Ghosh, Scripta Materialia 57, 813 (2007).

[10] C. J. Bong, K. S. Ryu, S. H. Nahm, and E. K. Kim, J. Magn. Magn. Mater. 323, 379 (2011).

[11] K. S. Ryu, S. H. Nahm, U. B. Baek, Y. H. Lee, J. S. Park, and M. G. Kim, International Conference of AUMS, CQ11, Jeju Island, Korea (2010).

[12] T. Goto, J. Soc. Mater. Sci. Japan 32, 103 (1983). 